\title{
Neonatal ventilatory techniques - which are best for infants born at term?
}

\author{
Olie Chowdhury, Anne Greenough
}

Division of Asthma, Allergy and Lung Biology, MRC Asthma Centre for Allergic Mechanisms of Asthma, King's College London, London, United Kingdom

Submitted: 5 August 2010

Accepted: 18 October 2010

Arch Med Sci 2011; 7, 3: 381-387

DOI: 10.5114/aoms.2011.23400

Copyright @ 2011 Termedia \& Banach

\section{Abstract}

Few studies have examined ventilatory modes exclusively in infants born at term. Synchronous intermittent mandatory ventilation (SIMV) compared to intermittent mandatory ventilation (IMV) is associated with a shorter duration of ventilation. The limited data on pressure support, volume targeted ventilation and neurally adjusted ventilatory assist demonstrate only short term benefits in term born infants. Favourable results of high-frequency oscillatory ventilation (HFOV) in infants with severe respiratory failure were not confirmed in the two randomised trials. Nitric oxide (NO) in term born infants, except in those with congenital diaphragmatic hernia $(\mathrm{CDH})$, reduces the combined outcome of death and requirement for extracorporeal membrane oxygenation (ECMO). In infants with severe refractory hypoxaemic respiratory failure, ECMO, except in infants with $\mathrm{CDH}$, reduced mortality and the combined outcome of death and severe disability at long-term follow-up. Randomised studies with long term outcomes are required to determine the optimum modes of ventilation in term born infants.

Key words: extracorporeal membrane oxygenation, high frequency oscillation, patient triggered ventilation, nitric oxide.

\section{Introduction}

Term-born infants require assisted ventilation for a variety of reasons, the most common being meconium aspiration syndrome (MAS), respiratory distress syndrome (RDS) and transient tachypnoea of the newborn (TTN) [1]. In a study of 65,000 term infants, the incidences of mechanical ventilation for MAS, RDS and TTN were $0.61,0.38$ and 0.72 per thousand live births respectively [1]. In a study of ventilated infants of at least 34 weeks of gestation, pneumonia/sepsis and persistent pulmonary hypertension of the newborn (PPHN) were also common diagnoses, approximately one third of the infants were ventilated for non pulmonary causes (Table I) [2]. It has been estimated that 3.6 per 1000 infants born at term require mechanical ventilation [1].

The mortality rate amongst term born infants requiring assisted ventilation is high, ranging from $9.1 \%$ to $11.7 \%[3,4]$. Although major congenital anomalies are a contributing factor, there is a high mortality rate $(9.6 \%$ to $12.2 \%)$ in ventilated, term born infants without major congenital anomalies [5]. Term born infants requiring mechanical ventilation also suffer considerable morbidity. In one study [2], 11\% developed chronic lung disease (defined as a requirement for supplemental

\author{
Corresponding author: \\ Prof. Anne Greenough \\ Neonatal Intensive \\ Care Centre \\ $4^{\text {th }}$ Floor Golden Jubilee Wing \\ King's College Hospital \\ Denmark Hill, London \\ SE5 8RS, UK \\ Phone: 02032993037 \\ Fax: 02032998284 \\ E-mail: \\ anne.greenough@kcl.ac.uk
}


Table I. Diagnoses of term and near-term neonates requiring mechanical ventilation [from 2]. The percentage of infants with a particular diagnosis are demonstrated

\begin{tabular}{|c|c|c|}
\hline \multirow[t]{7}{*}{ Pulmonary } & Respiratory distress syndrome & $43 \%$ \\
\hline & Meconium aspiration syndrome & $9.7 \%$ \\
\hline & Congenital pneumonia/sepsis & $8.3 \%$ \\
\hline & Transient tachypnoea of the newborn & $3.9 \%$ \\
\hline & $\begin{array}{l}\text { Persistent pulmonary hypertension } \\
\text { of the newborn }\end{array}$ & $3.2 \%$ \\
\hline & Aspiration of blood/amniotic fluid & $2.3 \%$ \\
\hline & Pulmonary hypoplasia & $1.4 \%$ \\
\hline \multirow[t]{4}{*}{$\begin{array}{l}\text { Non- } \\
\text { pulmonary }\end{array}$} & $\begin{array}{l}\text { Major congenital anomaly } \\
\text { eg. gastroschisis }\end{array}$ & $21 \%$ \\
\hline & Hypoxic-ischaemic encephalopathy & $3.1 \%$ \\
\hline & Peri-operative support & $2.1 \%$ \\
\hline & Undefined & $5.7 \%$ \\
\hline
\end{tabular}

oxygen at 30 days after birth) and 9\% developed neurological complications (defined as the development of prolonged seizures despite treatment, an abnormal electroencephalogram or abnormal brain imaging showing brain atrophy, intracranial haemorrhage or stroke).

There have been many studies attempting to optimise mechanical ventilation, but these have generally focused on prematurely born infants [6]. Prematurely born infants usually require ventilatory support because they have lung immaturity and/or inadequate respiratory control. In contrast, term born infants may have vigorous respiratory drive and can suffer from a variety of pathologies. Thus, it cannot be assumed that ventilation modes for prematurely born infants will be optimal for those born at term. We, therefore, have reviewed the literature (Table II) to determine if there are sufficient data to make evidence based recommendations regarding optimum ventilation for infants born at term.

\section{Time-cycled pressure-limited ventilation}

During intermittent mandatory ventilation (IMV) or intermittent positive pressure ventilation (IPPV) mechanical inflations are delivered at a pre-defined rate regardless of the infant's spontaneous respiratory activity. This can lead to asynchrony, resulting in pneumothorax [7]. In randomised trials $[8,9]$, use of "fast" ventilator rates (at least $60 \mathrm{bpm}$ ) was associated with a lower rate of pneumothoraces, but only in the prematurely born infants. In one study [8], ventilation at a rate of 60 breaths per minute (bpm) with a inspiratory time of $0.5 \mathrm{~s}$ was compared to a rate of $20-40 \mathrm{bpm}$ with a $1 \mathrm{~s}$ inspiratory time. The number of term born infants

Table II. Studies of neonatal ventilation in term babies

\begin{tabular}{|c|c|c|c|}
\hline Reference & Numbers included & Intervention & Design \\
\hline$[8]$ & 102 & $\begin{array}{l}\text { Rapid rate, short inflation time vs. slow rate, } \\
\text { long inflation time }\end{array}$ & $\begin{array}{l}\text { Alternate allocation } \\
\text { to each arm }\end{array}$ \\
\hline$[9]$ & 346 & $\begin{array}{c}\text { High frequency positive pressure ventilation } \\
\text { vs. low frequency positive pressure } \\
\text { ventilation }\end{array}$ & $\begin{array}{l}\text { Multicentre randomised } \\
\text { controlled trial }(\mathrm{RCT})\end{array}$ \\
\hline$[10]$ & 327 (included $93>2 \mathrm{~kg}$ ) & SIMV vs. IMV & Multicentre RCT \\
\hline [11] & 77 (included 15 term) & SIMV vs. IMV & RCT \\
\hline$[12]$ & 20 & SIMV + PS VS. SIMV & $\mathrm{RCT}$ \\
\hline$[13]$ & 9 & No PSV vs. PSV $5 \mathrm{~cm} \mathrm{H} \mathrm{H}_{2} \mathrm{O}$ vs. PSV $\left(10 \mathrm{~cm} \mathrm{H}_{2} \mathrm{O}\right)$ & Randomised crossover \\
\hline$[14]$ & 14 & PSV + VG vS. SIMV & Randomised crossover \\
\hline$[17]$ & 16 & PSV vs. NAVA & Crossover \\
\hline$[26]$ & 34 & HFJV & Case series \\
\hline$[27]$ & 176 & HFJV & Case series \\
\hline$[28]$ & 10 & HFJV & Case series \\
\hline$[29]$ & 37 & HFJV vs. conventional & Retrospective case-control \\
\hline$[31]$ & 24 & $\begin{array}{c}\text { HFJV vs. conventional high frequency positive } \\
\text { pressure ventilation }\end{array}$ & RCT \\
\hline [32] & 41 & HFOV & Case series \\
\hline [33] & 50 & HFOV & Case series \\
\hline [34] & 79 & HFOV vs. pressure-limited time-cycled ventilation & Multicentre RCT \\
\hline [35] & 118 & HFOV vs. conventional ventilation & Multicentre RCT \\
\hline
\end{tabular}


included in the study was not stated but the pneumothoraces all occurred in infants of birth weight less than $1.7 \mathrm{~kg}$ [8]. In another study (OCTAVE) [9], rates of $60 \mathrm{bpm}$ were compared to rates of 20-40 bpm in 346 ventilated infants without meconium aspiration. The infants suffered from a variety of diagnoses including RDS, TTN, pneumonia, PPHN and birth asphyxia; again, the number of term born infants was not stated. No significant difference in the pneumothorax rate was demonstrated overall, but in the infants born at less than 33 weeks of gestation it was significantly lower at 60 compared to 20-40 bpm [9]. The results of those studies $[8,9]$ suggest using ventilator rates of $60 \mathrm{bpm}$ rather than $20-40 \mathrm{bpm}$ is not advantageous in term infants with regard to reducing pneumothoraces and there are no other reported benefits.

\section{Patient-triggered ventilation}

During patient-triggered ventilation (PTV), the infant's respiratory efforts trigger mechanical inflations. During synchronised intermittent mandatory ventilation (SIMV) a pre-defined number of mechanical inflations are delivered, but during assist control ventilation (ACV) all the patient's respiratory efforts that exceed the critical trigger level are supported by mechanical inflations. Infants born at term have been included in two studies comparing SIMV and IMV $[10,11]$, they show only limited benefit of SIMV. A multicentre randomised trial [10] included 93 infants with a birth weight greater than $2 \mathrm{~kg}$ and a mean gestational age of 36 weeks; the study was adequately powered for subgroup analysis with respect to oxygenation index and the incidence of air leaks. Infants of birth weight greater than $2 \mathrm{~kg}$ supported by SIMV had a shorter duration of ventilation $(p=0.02)$, but had similar rates of death, air leak and oxygen dependency at 28 days. In the other randomised trial [11], there were no significant differences in the duration of ventilation, need for reintubation or pneumothorax or mortality rates between infants supported by SIMV or IMV, only 15 infants born at term (all with MAS) were included.

\section{Pressure support ventilation}

During pressure support ventilation (PSV), ventilator inflation is not only initiated by the baby's inspiratory effort, but is terminated when the infant's inspiratory flow declines to a predefined level. The level may be fixed (eg. 15\% of inspiratory flow with the Dräger Babylog 8000 plus) or can be varied by the clinician between $5 \%$ and $25 \%$ (VIP Bird and SLE 5000 ventilators). The data regarding the efficacy of PSV are limited, certain results suggest use of PSV might be advantageous in infants born at or near term $[12,13]$, but this is not a consistent finding [14]. In a study of 20 infants, including five infants born at term, addition of pressure support to SIMV compared to SIMV alone was associated with a reduction in the work of breathing ( $p<0.001$ ); no sub-analysis, however, was done with respect to maturity at birth [12]. In nine term-born infants with congenital heart disease, studied post-operatively or post-cardiac catheterisation, increasing levels of pressure support added to continuous positive airway pressure (CPAP) was associated with increased tidal volumes, minute ventilation and inspiratory flow [13]. In contrast, in a crossover trial [14] of $4 \mathrm{~h}$ periods of PSV plus volume guarantee (VG) or SIMV including 14 infants with a mean gestational age of 34 weeks and birth weight of $2.5 \mathrm{~kg}$ recovering from RDS, although, minute ventilation and mean airway pressure were significantly higher and functional residual capacity significantly lower during PSV plus VG, there were no significant differences in the carbon dioxide levels, arterial/alveolar oxygen tension or dynamic compliance results according to ventilator mode. The authors concluded that PSV with VG could not be recommended [14], but others [15] have questioned the study design and data collection, including measuring dynamic compliance without assessing oesophageal pressure and hence the infant's contribution to the trans-pulmonary pressure changes.

\section{Proportional assist ventilation}

Proportional assist ventilation (PAV) is a more sophisticated form of PTV, during which the infant's spontaneous respiratory effort determines the frequency, timing and rate of lung inflation. The clinician can set levels of elastic and resistive unloading to reduce the infant's work of breathing. Clinical studies of PAV in infants have only included those born prematurely. An in vitro study, however, has been carried out using lung models which mimicked the lung function abnormalities, not only of infants with RDS and BPD, but also those with MAS [16]. It demonstrated that pressures delivered by the ventilator were between $1 \mathrm{~cm}$ to $4 \mathrm{~cm} \mathrm{H}_{2} \mathrm{O}$ in excess of those expected and oscillations appeared in the airway pressure wave form as the unloading was increased, the level being dependent on the lung function abnormalities of the lung model. There was also a delay in the delivery of airway pressure of at least $60 \mathrm{~ms}$ [16]. Unloading did reduce the inspiratory load, but it was concluded that the possible impact of the waveform abnormalities and time lag in the inflation pressure delivery needed careful evaluation in the clinical setting [16].

\section{Neurally adjusted ventilatory assist}

Neurally adjusted ventilatory assist (NAVA) uses diaphragmatic electrical activity (EAdi) to trigger 
and cycle off ventilator support. The EAdi signals are detected by electrodes which are mounted on a nasogastric tube which is positioned such that the electrode array spans the diaphragm. The clinician can set the level of ventilator assist as 'NAVA gain', which determines the magnitude of ventilator pressure delivered in relation to the EAdi. There are limited data on the use of NAVA in infants, but that available highlight short term benefits. NAVA was compared to PSV in a crossover designed study in infants and children, including seven infants born at term, six with congenital heart disease and one with a congenital diaphragmatic hernia [17]. Neurally adjusted ventilatory assist was associated with significantly better synchrony and lower peak airway pressures at $30 \mathrm{~min}$ and $3 \mathrm{~h}$ [17]. In another crossover study [18], NAVA was compared to PSV in 21 infants with a mean age of $2.9 \pm 2.1$ months studied after cardiac surgery. Three could not be ventilated with NAVA due to diaphragmatic paralysis but, in the remaining 18 infants, the peak inflating pressures and EAdi were significantly lower during NAVA without differences in the carbon dioxide clearance.

\section{Volume-targeted ventilation}

During volume-targeted ventilation (VTV), a predetermined volume is delivered despite changes in the infant's respiratory function. This is achieved by servo-controlled adjustments in the inflating pressure in response to differences in either the exhaled or inhaled volume. There are different forms of VTV: volume guarantee (VG), volume controlled, volume limited, pressure-regulated volume control (PRVC) and volume-assured pressure support (VAPS). Ventilator manufacturers have used different strategies to achieve VTV and this results in differences in the airway pressure wave form [19]. Volume-targeted ventilation can be used in conjunction with other modes such as IPPV, SIMV, ACV or PSV. In adults use of a higher $(12 \mathrm{ml} / \mathrm{kg})$ rather than a lower $(6 \mathrm{ml} / \mathrm{kg})$ tidal volume was associated with a significantly higher mortality rate [20] and larger volumes are also more likely to cause endothelial and peripheral airway injury [21]. In a randomised trial $(n=22)$, infants aged 1 to 9 months with congenital heart disease studied post-operatively who were ventilated with VT levels of $10-12 \mathrm{ml} / \mathrm{kg}$ rather than $6-8 \mathrm{ml} / \mathrm{kg}$ had significantly higher serum levels of the proinflammatory cytokine interleukin-6, as well as a trend to worsening oxygenation [22]. Evidence from prematurely born infants, however, highlights that too a low tidal volume should also be avoided $[23,24]$. Increased levels of inflammatory markers in tracheal aspirates were found when a volume target level of $3 \mathrm{ml} / \mathrm{kg}$ rather than $5 \mathrm{ml} / \mathrm{kg}$ was used [23] and in another study [24], there was an increased work of breathing at $4 \mathrm{ml} / \mathrm{kg}$ compared to levels of 5 and $6 \mathrm{ml} / \mathrm{kg}$ [24]. The optimum VT level in term born infants and whether this varies according to the type of respiratory pathology needs to be determined.

\section{High frequency jet ventilation}

During high frequency jet ventilation (HFJV), brief pulses of gas at high pressure are delivered through a small-bore injector cannula in a triple-lumen endotracheal tube or via an adapter attached to the proximal end of an endotracheal tube. A constant background of positive end expiratory pressure (PEEP) is provided by a conventional ventilator operating in tandem. Rates of 200-600 per minute are used and the high velocity pulses of gas entrain humidified gas down the endotracheal tube. Non controlled studies reported results of HFJV in both term and preterm infants. In the earlier studies [25, 26], use of HFJV was associated with a significant improvement in both oxygenation and carbon dioxide tensions, but fatal necrotising tracheobronchitis was a major complication. In addition, in one study [26] fatal pneumopericardia occurred in 3 out of 23 patients with air leaks. A subsequent study [27] also highlighted significant improvements in $\mathrm{PaO}_{2}$ and $\mathrm{PaCO}_{2}$ at lower $\mathrm{FiO}_{2}$, PIP and MAP levels on HFJV, but only a $4 \%$ rate of necrotising tracheobronchitis and a $3 \%$ rate of pneumopericardium. Friedlich et al. [28] also reported HFJV resulted in significant reductions in the oxygenation index, $\mathrm{FiO}_{2}$ and MAP levels in neonates with hypoxaemia refractory to HFOV. A retrospective comparison of 14 term neonates with PPHN treated with HFJV with 23 similar infants treated with conventional ventilation demonstrated that the infants supported by HFJV had significantly lower oxygen indices (OI), $\mathrm{PaCO}_{2}$ and MAP levels [29]. There were, however, no significant differences between the two groups in their alveolar-arterial oxygen gradients, incidence of air leaks or bronchopulmonary dysplasia (BPD) or their durations of ventilation or supplementary oxygen dependencies [29]. A retrospective evaluation of the role of HFJV prior to ECMO in 73 term neonates reported those with severe meconium aspiration or congenital diaphragmatic hernia were less likely to respond to HFJV compared to infants with other causes of respiratory failure [30]. There has been only one randomised controlled trial comparing HFJV to high frequency positive pressure ventilation (HFPPV) in term and near-term infants, it included 24 infants with respiratory failure and PPHN [31]. The HFJV group experienced a significant acute rise in $\mathrm{PaO}_{2}$ and a decrease in $\mathrm{PaCO}_{2}$ and OI, whereas the HFPPV group required a significant increase in their peak inflating pressures to maintain gas 
exchange. There were no significant differences in the rates of survival without ECMO, air leak or chronic lung disease or the duration of ventilation. One of 11 babies in HFJV arm developed tracheitis and one of 13 babies in the conventional arm tracheal obstruction [31].

\section{High-frequency oscillatory ventilation}

During high-frequency oscillatory ventilation (HFOV), small tidal volumes are delivered at fast rates, that is, greater than $5 \mathrm{~Hz}$. Two uncontrolled "rescue" studies showed a beneficial effect of HFOV in term born neonates with severe respiratory failure [32, 33]. In 41 infants with pulmonary hypertension due to a variety of conditions including TTN, pneumonia, MAS, RDS and Group B Streptococcal sepsis, three infants died and in four infants HFOV could not be successfully established [32]. In the remaining 34 infants, however, there was a significant rise in the mean arterial/alveolar oxygen tension ratio and reductions in the arterial carbon dioxide tension and mean airway pressure within $12 \mathrm{~h}$ of initiating HFOV [32]. In another series [33], 21 of 50 infants admitted for extracorporeal membrane oxygenation (ECMO) responded to HFOV. There were no significant differences between the infants who were rescued by HFOV and those who required ECMO with regard to their durations of ventilation or hospital stay or survival rates [33]. The results, however, from two multi-centre randomised controlled trials [34, 35], which have compared HFOV to conventional ventilation in term and near-term infants with severe respiratory failure, did not highlight benefits. One study [34] included infants of more than 34 weeks of gestational age and more than $2 \mathrm{~kg}$ in birth weight. The infants' diagnoses included pneumonia, RDS, MAS, pulmonary hypoplasia and air leak. No differences were detected in the rates of treatment failure, need for ECMO, chronic lung disease or survival or the duration of ventilation, but $63 \%$ of the 24 infants, assigned to conventional ventilation and meeting treatment failure criteria, responded to HFOV. The trial, however, was prematurely terminated ( $n=79$, sample size calculation 250) due to difficulty in recruitment. In the second study [35], which included newborns of more than 35 weeks of gestation and birth weight greater than $1.75 \mathrm{~kg}$, there were no significant differences in either the primary (death and pulmonary air leak) or secondary (chronic lung disease, duration of ventilation and treatment failure) outcomes. The planned sample size was 200 babies, but the study was terminated when 118 infants had been recruited as the interim analysis did not demonstrate any statistically significant difference in the primary outcome. The Cochrane review [36] of HFOV vs. conventional ventilation in term or near-term infants with severe respiratory failure analysed data from those two studies [34, 35 ] and concluded that there was no evidence to support the use of HFOV in term and near-term infant with severe respiratory failure.

\section{Nitric oxide}

Inhaled NO (iNO) is a selective pulmonary vasodilator and is used in severe hypoxaemic respiratory failure associated with pulmonary hypertension. The Cochrane review [37] of iNO for respiratory failure in term and near-term infants includes 14 studies. Meta-analysis of the results of those 14 trials highlighted that use of iNO was associated with a significant reduction in the combined outcome of death or requirement for ECMO (relative rate (RR) 0.68 , 95\% confidence intervals $(\mathrm{Cl})$ 0.59-0.79). There was no significant difference in the mortality rate $(\mathrm{RR} 0.91,95 \% \mathrm{Cl} 0.6$ 1.37), but a significant reduction in the requirement for ECMO (RR 0.63, 95\% Cl 0.54-0.75). In a subgroup of 84 infants with $\mathrm{CDH}$, there were no significant differences in the combined outcome of death or requirement for ECMO (RR 1.09, 95\% Cl 0.95-1.26) or mortality rate (RR $1.2,95 \% \mathrm{Cl} 0.74-1.96)$ and a marginally significant increase in the requirement for ECMO (RR 1.27, 95\% Cl 1.00-1.62).

\section{Extracorporeal membrane oxygenation}

Extracorporeal membrane oxygenation (ECMO) is a form of cardiopulmonary bypass. In venoarterial (VA) ECMO, blood is drained from the right atrium via the right internal jugular vein and returned to the aorta via the right carotid artery, total cardiopulmonary bypass is achieved. In veno-

Table III. Neonatal ECMO

\begin{tabular}{|c|c|}
\hline \multirow[t]{9}{*}{ Suitability } & Gestational age $\geq 34$ weeks \\
\hline & Birth weight $\geq 2000 \mathrm{~g}$ \\
\hline & Reversible pulmonary disease \\
\hline & $\begin{array}{l}\text { Duration of mechanical ventilation } \\
<10-14 \text { days }\end{array}$ \\
\hline & $\begin{array}{l}\text { No significant coagulopathy } \\
\text { or active bleeding }\end{array}$ \\
\hline & No major intracranial haemorrhage \\
\hline & No lethal congenital malformation \\
\hline & No uncorrectable congenital heart disease \\
\hline & No evidence of irreversible brain damage \\
\hline \multirow{4}{*}{$\begin{array}{l}\text { Respiratory } \\
\text { status } \\
{[39,40]}\end{array}$} & Oxygenation index (OI) 35-60 for 0.5-6 h \\
\hline & $\mathrm{PaO}_{2}<35$ to $<60 \mathrm{mmHg}$ for $2-12 \mathrm{~h}$ \\
\hline & Arterial $\mathrm{pH}<7.25$ for $2 \mathrm{~h}$ or with hypotension \\
\hline & $\begin{array}{l}\text { Acute deterioration of } \mathrm{PaO}_{2} \text { to }<30 \\
\text { to }<40 \mathrm{mmHg}\end{array}$ \\
\hline
\end{tabular}


venous (VV) ECMO, blood is drained from and returned to the right atrium via a double-lumen catheter. The advantage of VA ECMO is that approximately $80 \%$ cardiopulmonary bypass is achieved and thus the level of respiratory support can be reduced. During VV ECMO, carotid artery cannulation is avoided, but the infant must have good myocardial function. Indications for ECMO have included an oxygenation index of more than 40 on two or more arterial blood gases [38] (Table III). The UK collaborative study [39] is the largest randomised study evaluating ECMO in neonates and demonstrated ECMO was associated with a $45 \%$ reduction in mortality in infants of greater that 34 weeks of gestation with severe respiratory failure. The Cochrane review [40] of ECMO for severe respiratory failure in newborns assessed four trials, including the UK collaborative study. Metaanalysis of the results of those four trials indicated that ECMO significantly reduced death (RR 0.51, $95 \% \mathrm{Cl} 0.37$ to 0.7 ), especially for babies without $\mathrm{CDH}$ (RR $0.41,95 \% \mathrm{Cl} 0.27$ to 0.63). Long term follow-up of the UK collaborative study has demonstrated a reduction in the combined outcome of death or severe disability at 1 (RR 0.56 , $95 \% \mathrm{Cl} 0.40$ to 0.78 ) [39], at 4 [41] and 7 years [42] (RR $0.62,95 \% \mathrm{Cl} 0.45$ to 0.86 ).

\section{Liquid ventilation}

Liquid ventilation is achieved by instillation of perfluorocarbons (PFC) into the lungs. Perfluorocarbons are inert compounds with low surface tension and high solubility for oxygen and carbon dioxide. Total liquid ventilation involves completely filling the lungs and ventilator circuit with PFC, whereas partial liquid ventilation (PLV) involves filling the lungs with PFC to approximately the functional residual capacity and then applying "on top" conventional ventilation. Data from in vitro studies suggest there could be numerous advantages to using liquid ventilation [43], but clinical data including term born infants are limited. Hirschl et al. [44] included five term born infants (four with $\mathrm{CDH}$ and one with PPHN) in a study of PLV in adults, children and infants with severe respiratory failure on ECMO [40]. Significant improvements in the alveolar-arterial oxygen difference and static pulmonary compliance were noted on commencement of PLV. Use of PLV was associated with few adverse events, but there was re-accumulation of pneumothoraces in 6 patients, development of new pneumothoraces in three and patients and there was extravasation of PFC into the pleural space in 3 patients with pneumothoraces. Further studies are required to determine if liquid ventilation offers advantages over other respiratory support techniques in term born neonates.

\section{Recommendations}

- Infants should be started on time cycled, pressure limited ventilation at rates of 30 to $40 \mathrm{bpm}$.

- Infants with evidence of pulmonary hypertension should receive inhaled nitric oxide.

- Infants with severe respiratory failure should be referred for consideration of ECMO except infants with congenital diaphragmatic hernia who should be considered on a case by case basis.

\section{Research directions}

- All new modes of ventilatory support for use in term born infants should be optimised using in vivo models and then studies with physiological outcomes, in particular determining if optimal modes very with the underlying diagnosis.

- Subsequently, appropriately designed studies with long term outcomes need to be undertaken.

\section{Acknowledgments}

Dr Chowdhury is supported by a grant from the Charles Wolfson Charitable Trust. We thank Mrs Deirdre Gibbons for secretarial assistance.

\section{References}

1. Gouyon JB, Ribakovsky C, Ferdynus C, et al. Severe respiratory disorders in term neonates. Paediatr Perinat Epidemiol 2008; 22: 22-30.

2. Clark RH. The epidemiology of respiratory failure in neonates born at an estimated gestational age of 34 weeks or more. J Perinatol 2005; 25: 251-7.

3. Lian W, Yeo CL, Ho LY. Two-year outcome of normal-birthweight infants admitted to a Singapore neonatal intensive care unit. Ann Acad Med Singapore 2002; 31: 199-205.

4. Angus DC, Linde-Zwirble WT, Clermont G, Griffin MF, Clark RH. Epidemiology of neonatal respiratory failure in the United States: projections from California and New York. Am J Respir Crit Care Med 2001; 164: 1154-60.

5. Sutton L. Population-based data on full-term neonates with severe morbidity. Sem Neonatol 1997; 2: 189-93.

6. Greenough A, Patel DS. Neonatal ventilation techniques - which is best for prematurely born infants? Arch Med Sci 2008; 2: 116-21.

7. Greenough A, Morley C, Davis J. Interaction of spontaneous respiration with artificial ventilation in preterm babies. J Pediatr 1983; 103: 769-73.

8. Heicher DA, Kasting DS, Harrod JR. Prospective clinical comparison of two methods for mechanical ventilation of neonates: rapid rate and short inspiratory time versus slow rate and long inspiratory time. J Pediatr 1981; 98: 957-61.

9. Oxford Region Controlled Trial of Artificial Ventilation OCTAVE Study Group. Multicentre randomised controlled trial of high against low frequency positive pressure ventilation. Arch Dis Child 1991; 66: 770-5.

10. Bernstein G, Mannino FL, Heldt GP, et al. Randomized multicenter trial comparing synchronized and conventional intermittent mandatory ventilation in neonates. J Pediatr 1996; 128: 453-63. 
11. Chen JY, Ling UP, Chen JH. Comparison of synchronized and conventional intermittent mandatory ventilation in neonates. Acta Paediatr Japonica 1997; 39: 578-83.

12. Patel DS, Rafferty GF, Lee S, Hannam S, Greenough A. Work of breathing during SIMV with and without pressure support. Arch Dis Child 2009; 94: 434-6.

13. Tokioka H, Nagano O, Ohta Y, Hirakawa M. Pressure support ventilation augments spontaneous breathing with improved thoracoabdominal synchrony in neonates with congenital heart disease. Anesth Analg 1997; 85: 789-93.

14. Olsen SL, Thibeault DW, Truog WE. Crossover trial comparing pressure support with synchronized intermittent mandatory ventilation. J Perinatol 2002; 22: 461-6.

15. Keszler M, Abubakar KM, Mammel MC. Response to Olsen, et al. Study comparing SIMV and PSV. J Perinatol 2003; 23: 434-5.

16. Patel DS, Rafferty GF, Hannam S, Lee S, Milner AD, Greenough A. In vitro assessment of proportional assist ventilation. Arch Dis Child 2010 [Epub ahead of print].

17. Breatnach C, Conlon NP, Stack M, Healy M, O'Hare BP. A prospective crossover comparison of neurally adjusted ventilatory assist and pressure-support ventilation in a pediatric and neonatal intensive care unit population. Pediatr Crit Care Med 2010; 11: 7-11.

18. Zhu LM. [Application of neurally adjusted ventilatory assist in infants who underwent cardiac surgery for congenital heart disease]. Zhongguo Dang Dai Er Ke Za Zhi 2009; 11: 433-6.

19. Sharma A, Milner AD, Greenough A. Performance of neonatal ventilators in volume targeted ventilation mode. Acta Paediatr 2007; 96: 176-80.

20. The Acute Respiratory Distress Syndrome Network. Ventilation with lower tidal volumes as compared with traditional tidal volumes for acute lung injury and the acute respiratory distress syndrome. N Engl J Med 2000; 342: 1301-8.

21. Pelosi P, Negrini D. Extracellular matrix and mechanical ventilation in healthy lungs: back to baro/volotrauma? Curr Opin Crit Care 2008; 14: 16-21.

22. Umenai T, Shime N, Hashimoto S. Hyperventilation versus standard ventilation for infants in postoperative care for congenital heart defects with pulmonary hypertension. J Anesth 2009; 23: 80-6.

23. Lista G, Castoldi F, Fontana $P$, et al. Lung inflammation in preterm infants with respiratory distress syndrome: effects of ventilation with different tidal volumes. Pediatr Pulmonol 2006; 41: 357-63.

24. Patel D, Sharma A, Prendergast M, Rafferty GF, Greenough A. Work of breathing and different levels of volumetargeted ventilation. Pediatrics 2009; 123: e679-84.

25. Pokora T, Bing D, Mammel M, Boros S. Neonatal highfrequency jet ventilation. Pediatrics 1983; 72: 27-32.

26. Boros SJ, Mammel MC, Coleman JM, et al. Neonatal highfrequency jet ventilation: four years' experience. Pediatrics 1985; 75: 657-63.

27. Spitzer AR, Butler S, Fox WW. Ventilatory response to combined high frequency jet ventilation and conventional mechanical ventilation for the rescue treatment of severe neonatal lung disease. Pediatr Pulmonol 1989; 7: 244-50.

28. Friedlich P, Subramanian N, Sebald M, Noori S, Seri L. Use of high-frequency jet ventilation in neonates with hypoxemia refractory to high-frequency oscillatory ventilation. J Matern Fetal Neonatal Med 2003; 13: 398-402.

29. Carlo WA, Beoglos A, Chatburn RL, Walsh MC, Martin RJ. High-frequency jet ventilation in neonatal pulmonary hypertension. Am J Dis Child 1989; 143: 233-8.
30. Baumgart S, Hirschl RB, Butler SZ, Coburn CE, Spitzer AR. Diagnosis-related criteria in the consideration of extracorporeal membrane oxygenation in neonates previously treated with high-frequency jet ventilation. Pediatrics 1992; 89: 491-4.

31. Engle WA, Yoder MC, Andreoli SP, Darragh RK, Langefeld $\mathrm{CD}$, Hui SL Controlled prospective randomized comparison of high-frequency jet ventilation and conventional ventilation in neonates with respiratory failure and persistent pulmonary hypertension. J Perinatol 1997; 17: 3-9.

32. Kohelet D, Perlman M, Kirpalani H, Hanna G, Koren G. High-frequency oscillation in the rescue of infants with persistent pulmonary hypertension. Crit Care Med 1988; 16: $510-6$.

33. Carter J, Gerstmann DR, Clark RH, et al. High-frequency oscillatory ventilation and extracorporeal membrane oxygenation for the treatment of acute neonatal respiratory failure. Pediatrics 1990; 85: 159-64.

34. Clark RH, Yoder BA, Sell MS. Prospective, randomized comparison of high-frequency oscillation and conventional ventilation in candidates for extracorporeal membrane oxygenation. J Pediatr 1994; 124: 447-54.

35. Rojas MA, Lozano JM, Rojas MX, et al. Randomized, multicenter trial of conventional ventilation versus highfrequency oscillatory ventilation for the early management of respiratory failure in term or near-term infants in Colombia. J Perinatol 2005; 25: 720-4.

36. Henderson-Smart DJ, De Paoli AG, Clark RH, Bhuta T. High frequency oscillatory ventilation versus conventional ventilation for infants with severe pulmonary dysfunction born at or near term. Cochrane Database Syst Rev 2009; 3: CD002974.

37. Finer NN, Barrington KJ. Nitric oxide for respiratory failure in infants born at or near term. Cochrane Database Syst Rev 2006; 4: CD000399.

38. Van Meurs K, Peek G, Zwischenberger JB. ECMO Extracorporeal Cardiopulmonary Support in Critical Care. 3rd ed. 2005 Ann Arbor, MI: Extracorporeal Life Support Organisation.

39. UK Collaborative ECMO Trial Group. UK collaborative randomised trial of neonatal extracorporeal membrane oxygenation. Lancet 1996; 348: 75-82.

40. Elbourne D, Field D, Mugford M. Extracorporeal membrane oxygenation for severe respiratory failure in newborn infants. Cochrane Database Syst Rev 2002; 1: CD001340.

41. UK Collaborative ECMO Trial Group. UK collaborative randomised trial of neonatal extracorporeal membrane oxygenation: follow up to age 4 years. Lancet 2001; 357: 1094-6.

42. UK Collaborative ECMO Trial Group. UK collaborative randomised trial of neonatal extracorporeal membrane oxygenation: follow up to age 7 years. Pediatrics 2006; 117: e845-54.

43. Wolfson MR, Shaffer TH. Pulmonary applications of perfluorochemical liquids: ventilation and beyond. Paediatr Respir Rev 2005; 6: 117-27.

44. Hirschl RB, Pranikoff T, Gauger P, Schreiner RJ, Dechert R, Bartlett RH. Liquid ventilation in adults, children, and fullterm neonates. Lancet 1995; 346: 1201-2. 